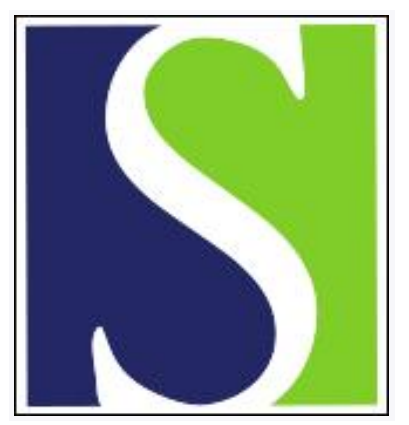

Scand J Work Environ Health 2011;37(5):376-382

https://doi.org/10.5271/sjweh.3167

Published online: 28 Apr 2011, Issue date: Sep 2011

Sickness absence associated with shared and open-plan offices - a national cross sectional questionnaire survey by Pejtersen JH, Feveile H, Christensen KB, Burr H

Affiliation: Danish National Centre for Social Research, Herluf Trolles Gade 11,·DK-1052 Copenhagen K, Denmark. jhp@sfi.dk

The following articles refer to this text: 2011;37(5):359-362;

2018;44(3):330-334; 2020;46(3):330-334; 2021;47(1):22-32;

2023;49(3):222-230

Key terms: office building; open-plan office; shared office; sick leave; sickness absence; work environment

This article in PubMed: www.ncbi.nlm.nih.gov/pubmed/21528171

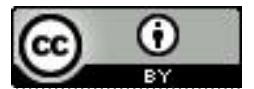




\title{
Sickness absence associated with shared and open-plan offices - a national cross sectional questionnaire survey
}

\author{
by Jan H Pejtersen, PhD, ${ }^{1}$ Helene Feveile, PhD, ${ }^{1}$ Karl B Christensen, PhD, ${ }^{2}$ Hermann Burr, PhD ${ }^{1}$
}

\begin{abstract}
Pejtersen JH, Feveile H, Christensen KB, Burr H. Sickness absence associated with shared and open-plan offices a national cross sectional questionnaire survey. Scand J Work Environ Health 2011;37(5):376-382. doi:10.5271/ sjweh.3167
\end{abstract}

\begin{abstract}
Objective The aim of this study was to examine whether shared and open-plan offices are associated with more days of sickness absence than cellular offices comprising one occupant.

Methods The analysis was based on a national survey of Danish inhabitants between 18-59 years of age (response rate 62\%), and the study population consisted of the 2403 employees that reported working in offices. The different types of offices were characterized according to self-reported number of occupants in the space. The log-linear Poisson model was used to model the number of self-reported sickness absence days depending on the type of office; the analysis was adjusted for age, gender, socioeconomic status, body mass index, alcohol consumption, smoking habits, and physical activity during leisure time.
\end{abstract}

Results Sickness absence was significantly related to having a greater number of occupants in the office $(\mathrm{P}<0.001)$ when adjusting for confounders. Compared to cellular offices, occupants in 2-person offices had 50\% more days of sickness absence [rate ratio (RR) 1.50, 95\% confidence interval (95\% CI) 1.13-1.98], occupants in 3-6-person offices had 36\% more days of sickness absence (RR 1.36, 95\% CI 1.08-1.73), and occupants in open-plan offices ( $>6$ persons) had 62\% more days of sickness absence (RR 1.62, 95\% CI 1.30-2.02).

Conclusion Occupants sharing an office and occupants in open-plan offices ( $>6$ occupants) had significantly more days of sickness absence than occupants in cellular offices.

Key terms office building; sick leave; work environment.

Sickness absence is an important public health problem with an impact on employees, the employer, and society in general (1-3). Risk factors for sickness absence have been the topic of many studies (4), but so far only a few have related sickness absence to the indoor environment in offices (5). Danielsson \& Bodin (6) studied the association between self-reported sick leave and type of office characterized by a combination of functional features of the offices and number of occupants. The type of office showed no association with the risk of sick leave ( $>7$ days/year), but an association between the type of office and being sick at least one day per year was found. Sharing an office has shown to be a risk factor for more than two episodes of common cold during a year compared to workers having private offices (7). In an observational study, Milton et al (8) found an asso- ciation between sickness absence and lower ventilation rates per person in offices. However, in an experimental intervention study, no relation between ventilation rate and sick leave was found (9).

Studies have found that sickness absence was associated with mechanical ventilation (10) and air-conditioning (11), and cleaning the ventilation system may reduce the prevalence of symptoms and the absenteeism rate (5). Mechanical ventilation has been associated with an elevated prevalence of non-specific symptoms in office buildings in several studies $(12,13)$; open-plan offices are more likely to have mechanical ventilation than cellular offices to be able to cope with building regulations (14).

We have previously reported that the prevalence of indoor environmental complaints and non-specific

1 National Research Centre for the Working Environment, Copenhagen, Denmark.

2 Institute of Public Health, Department of Biostatistics, University of Copenhagen, Copenhagen, Denmark.

Correspondence to: Jan H Pejtersen, Danish National Centre for Social Research, Herluf Trolles Gade 11, DK-1052, Copenhagen K, Denmark. [E-mail:jhp@sfi.dk]. 
symptoms among office workers increased with an increasing number of occupants in the space (14). However, in a review of non-specific symptoms among office workers, only 7 out of 32 studies included the number of office workers in the space (12). Five of these found the number of office workers to be positively associated with prevalence of symptoms. This is in accordance with recent studies $(7,15-18)$.

The most prevalent complaint in open-plan offices is noise annoyance $(14,19)$, with ringing phones and other peoples' conversation being the most annoying sources of noise (20). In open-plan offices, employees perceive they have less privacy and find it difficult to have undisturbed and confidential conversations (21). However, to our knowledge, no studies have related noise to sickness absence solely in office buildings.

Several studies have found that psychosocial risk factors predict sickness absence (22-24). One of these has been performed among office workers but did not include the number of workers per office (24). In our previous study, we found a significant association between employees' psychosocial work environment and the type of office for a number of psychosocial dimensions (14), but differences were below what is regarded as meaningful (25). However, a review found strong evidence that working in open-plan offices reduced employees' privacy and job satisfaction (19).

The aim of this study was to investigate whether shared and open-plan offices were associated with a higher number of days of sickness absence than cellular offices.

\section{Methods}

This study is based on the 2005 wave of the Danish Work Environment Cohort Study (DWECS) (26). The main components of DWECS are cohorts of random samples of adults registered in the Danish centralized civil register (CRS).

The analysis is based on a representative sample of Danish inhabitants, who had not requested survey exemption (27), were between 18-59 years of age, and were assigned to receive a mailed questionnaire. Respondents who had been employees within two months prior to the survey were classified as employees and responded to questions about working conditions and health behavior. The sample consisted of 14969 persons of which 9252 participated (62\%), 7219 of these were employees. This study is based on the 2403 (33\% of the 7219) employees that reported working in offices most of their time at work.

Type of workplace was assessed with the question "Where do you spend most of your time at work?"
Response options were: (i) outside; (ii) vehicle (for example, car, truck, work machine, train, ship); (iii) workshop or production area, with colleagues (indicate how many); (iv) workshop, production area without colleagues; (v) location where there are customers, clients, patients, students, children; (vi) office or openplan office (multiple workers in the same space), with colleagues (indicate how many); (vii) office without colleagues; (viii) indoors, other, indicate what:

Respondents were classified as working in offices if they used the $7^{\text {th }}$ response category or the $6^{\text {th }}$ response category together with a response to the question about number of colleagues.

Office workers were divided into four categories according to type of office: (i) cellular offices comprising one occupant, (ii) shared offices comprising two occupants, (iii) shared offices comprising three to six occupants, and (iv) open-plan offices comprising more than six occupants.

Sickness absence was assessed with the question "In total, how many sick days have you taken in the last year? Number of days: _."

Body mass index (BMI) was calculated from selfreported weight and height and categorized according to the standard classification of the World Health Organization (WHO) (28). The population was divided into heavy smokers ( $\geq 15$ cigarettes/day), moderate smokers ( $<15$ cigarettes/day), ex-smokers and non-smokers. Men were classified as having a high consumption of alcohol if their consumption on average exceeded three units per day. Women were classified as high consumers if they on average reported more than two units per day.

Physical activity during leisure time in the last year was measured with a single question (29). The four response categories were: (i) physically inactive/light physical activity $<2$ hours per week; (ii) light physical activity $2-4$ hours per week; (iii) physically active $\geq 4$ hours per week or more vigorous physical activity $2-4$ hours per week; (iv) more vigorous physical activity and competitive sports several times per week ( $>4$ hours per week).

Socioeconomic status was divided into six classes based on self-reported information on employment grade, job title, and education (30).

The distributions of age, gender, socioeconomic status, BMI, alcohol consumption, smoking habits, and physical activity during leisure time according to the various types of offices are given in table 1. Among the respondents working in offices, 2308 (96\%) answered the question concerning sickness absence. As sickness absence is a rare event, Poisson regression was used to model the number of self-reported sickness absence days. The analysis was adjusted for age, gender, socioeconomic status, BMI, alcohol consumption, smoking habits and physical activity during leisure time $(31,32)$ 
Table 1. Characteristic of the study population in the various office types. [SD=standard deviation.]

\begin{tabular}{|c|c|c|c|c|c|c|c|c|c|c|c|c|c|c|}
\hline \multirow[t]{3}{*}{ Characteristic } & \multicolumn{11}{|c|}{ Office type [number of occupants] } & & & \\
\hline & \multicolumn{3}{|c|}{$1(N=543)$} & \multicolumn{3}{|c|}{$2(\mathrm{~N}=268)$} & \multicolumn{3}{|c|}{$3-6(N=637)$} & \multicolumn{2}{|c|}{$>6(\mathrm{~N}=955)$} & \multicolumn{3}{|c|}{ Total $(\mathrm{N}=2403)$} \\
\hline & $\%$ & Mean & $\mathrm{SD}$ & $\%$ & Mean & SD & $\%$ & Mean & SD & $\%$ & Mean SD & $\%$ & Mean & SD \\
\hline Age (years) ${ }^{1}$ & & 46.0 & 9.2 & & 42.6 & 9.1 & & 41.0 & 9.8 & & 41.110 .1 & & 42.4 & 9.9 \\
\hline Gender (women) & 53 & & & 66 & & & 60 & & & 50 & & 55 & & \\
\hline \multicolumn{15}{|l|}{ Socioeconomic status } \\
\hline Higher white-collar & 47 & & & 35 & & & 28 & & & 32 & & 35 & & \\
\hline Middle white-collar & 25 & & & 22 & & & 21 & & & 20 & & 21 & & \\
\hline Lower white-collar & 22 & & & 34 & & & 42 & & & 40 & & 36 & & \\
\hline Skilled workers & 3 & & & 7 & & & 4 & & & 5 & & 4 & & \\
\hline Unskilled workers & 4 & & & 2 & & & 2 & & & 2 & & 2 & & \\
\hline In process of training & 0 & & & 0 & & & 2 & & & 2 & & 1 & & \\
\hline \multicolumn{15}{|l|}{ Body mass index (BMI) } \\
\hline$<18.5$ (underweight) & 1 & & & 2 & & & 1 & & & 2 & & 1 & & \\
\hline $18.5-24.9$ (normal) & 54 & & & 60 & & & 59 & & & 60 & & 59 & & \\
\hline 25-29.9 (overweight) & 36 & & & 31 & & & 29 & & & 31 & & 32 & & \\
\hline$\geq 30$ (obese) & 9 & & & 7 & & & 10 & & & 7 & & 8 & & \\
\hline \multicolumn{15}{|l|}{ Smoking habits } \\
\hline Non-smokers & 43 & & & 49 & & & 50 & & & 51 & & 49 & & \\
\hline Ex-smokers & 34 & & & 28 & & & 26 & & & 28 & & 29 & & \\
\hline Moderate smokers ( $<15$ cigarettes/day) & 9 & & & 12 & & & 11 & & & 12 & & 11 & & \\
\hline Heavy smokers ( $\geq 15$ cigarettes/day) & 15 & & & 10 & & & 13 & & & 9 & & 9 & & \\
\hline \multicolumn{15}{|l|}{ Alcohol consumption } \\
\hline $\begin{array}{l}\text { High consumption (men: }>3 \text { units per day; } \\
\text { women: }>2 \text { units per day) }\end{array}$ & 16 & & & 13 & & & 16 & & & 15 & & 15 & & \\
\hline \multicolumn{15}{|l|}{ Physical activity during leisure time } \\
\hline Physically active $<2$ hours/week & 18 & & & 16 & & & 17 & & & 17 & & 17 & & \\
\hline Light physical activity 2-4 hours/week & 58 & & & 63 & & & 59 & & & 58 & & 58 & & \\
\hline $\begin{array}{l}\text { Physically active }>4 \text { hours/week or more } \\
\text { vigorous physical activity } 2-4 \text { hours/week }\end{array}$ & 22 & & & 18 & & & 21 & & & 22 & & 22 & & \\
\hline $\begin{array}{l}\text { More vigorous physical activity and competitive } \\
\text { sports several times per week, }>4 \text { hours per week }\end{array}$ & 3 & & & 3 & & & 3 & & & 3 & & 3 & & \\
\hline
\end{tabular}

${ }^{1}$ Age, November 2005

and a scale parameter was added to account for overdispersion. A total number of 2202 respondents with non-missing data entered in this analysis.

\section{Results}

The average and median number of days of absence from work due to sickness during the last year for the occupants in the various types of offices is shown in table 2. The occupants in shared or open-plan offices reported almost twice as many days of sickness absence compared to occupants in private offices.

The rate ratios (RR) for sickness absence in the various office types are shown in table 3. Sickness absence was significantly related to type of office when adjusting for age, gender, socioeconomic status, BMI, alcohol consumption, smoking habits, and physical activity during leisure time $(\mathrm{P}<0.001)$. The occupants in 2 - and 3-6-person offices had on average, respectively $50 \%$ and $36 \%$ more days of sickness absence than occupants in cellular offices, while the occupants in open-plan offices ( $>6$ persons) had on average $62 \%$ more days of sickness absence than occupants in cellular offices.

\section{Discussion}

The strength of this study is the use of a national population sample. In contrast to other studies of open-plan offices $(6,14)$, this study represents more than 2000 different offices. To our knowledge this is the first national population study that has related sickness absence to type of office.

A weakness of the study is that both the type of office classification and sickness absence are based on self-report and associations may be influenced by common method bias (33). Reporting of sickness absence during the last 12 months may be influenced by recall bias (34), but the reporting of the number of occupants in the space is less likely to be affected by memory. The distribution of the number of occupants in the space (data not shown), showed that the reporting was subject to end-digit preference above ten occupants (35). This 
Table 2. Self-reported days of sickness absence within the last year according to office types.

\begin{tabular}{lccc}
\hline $\begin{array}{l}\text { Office type } \\
\text { [number of } \\
\text { occupants] }\end{array}$ & $\mathrm{N}$ & $\begin{array}{c}\text { Days of sickness } \\
\text { absence } \\
\text { (mean) }\end{array}$ & $\begin{array}{c}\text { Days of sickness } \\
\text { absence } \\
\text { (median) }\end{array}$ \\
\hline 1 & 522 & 4.9 & 1.0 \\
2 & 258 & 8.0 & 2.0 \\
$3-6$ & 610 & 7.1 & 2.0 \\
$>6$ & 918 & 8.1 & 2.0 \\
\hline
\end{tabular}

Table 3. Rate ratios for sickness absence in the various office types. The log-linear Poisson model was adjusted for age, gender, socioeconomic status, body mass index, alcohol consumption, smoking habits and physical activity during leisure time. [95\% Cl=95\% confidence interval.]

\begin{tabular}{lccc}
\hline $\begin{array}{l}\text { Office type [number } \\
\text { of occupants] }\end{array}$ & $\mathrm{N}$ & Rate ratios & $95 \% \mathrm{Cl}$ \\
\hline 1 & 497 & 1 & \\
2 & 250 & 1.50 & $1.13-1.98$ \\
$3-6$ & 584 & 1.36 & $1.08-1.73$ \\
$>6$ & 871 & 1.62 & $1.30-2.02$ \\
\hline
\end{tabular}

may be because respondents in larger offices pass from actually counting to roughly estimating the number of colleagues in the offices. Except for the end-digit preference peaks, the distribution was very similar to our previous study where the occupants were counted by a researcher (data not shown) (14). This indicates that the self-reported number of occupants $<10$ is valid, and since the offices were categorized into 1-, 2-, 3-6- and $>6$-person offices, the bias in relation to the end-digit preference had no influence on the found association.

Another weakness is that we do not know if the occupants have been in the same office for the entire recall period of 12 months. However, adjusting the model for length of employment in the company did not change the estimated rate ratios (data not shown). Although employees may change office within the company, we have no reason to believe that this should bias the results.

In all, 2308 respondents answered the question about sickness absence (table 2), but due to missing values for some of the covariates our analysis is based on 2202 occupants (table 3). The mean number of sickness absence days is higher for the group with missing data on covariates, but the pattern and relations between office categories are very similar to the overall sample (table 2). We do not think that the $4.5 \%$ missing data could influence the conclusion.

It would have been an advantage to have matched workplaces in each of the four categories of offices. However, by taking a random sample of employees, we are accounting for the fact that there is no matching on workplaces. Furthermore, by focusing on office workers, we are making the type of work comparable and also excluding workplaces and industries where employees experience sickness absence due to hard manual work etc. To further study this, we adjusted our model for differences in industries by using the 9-grouping for standard industrial grouping according to the 2003 Danish industrial classification of all economic activities (data not shown). We collapsed some of the smaller categories. The adjustment for industrial grouping had very little effect on the RR as they were reduced by only $2-4 \%$.

The validity of self-reported sickness absence has been studied among British civil servants, who mainly were office workers. The study found good agreement between self-reported sickness absence and registerbased sickness absence (36). The mean absence rates for the British civil servants were 7.1 days per year based on self-reported data and 7.3 days per year based on recorded data. This is similar to the mean absence rate of 7.1 days per year in our study. We therefore believe that self-reported sickness absence is a valid measure.

In Danish national surveys, there are increasing proportions of non-responders especially among young persons, and survey exception is four times more common among the age group 20-29 years than in the age group 50-59 years (27). In this study, we saw a slight trend towards decreasing age with increasing number of occupants in the space (table 1), and as other studies have shown that increasing age were a risk factor for self-reported sickness absence (31), we have ageadjusted the analysis. Nevertheless, we might have problems concerning the representativeness of the young responders if the non-responders and those with survey exception differ from respondents when it comes to both type of office and self-reported sickness absence. Persons with higher education are least inclined to request survey exemption (27) and non-responders have lower socioeconomic status and worse health than responders according to a Danish population-based study (37). The under-representation of the age group 20-29 years most likely resulted in bias towards an underestimation of the association, assuming that lower socioeconomic status is associated with more occupants in the office.

This study is cross-sectional and cannot explain the mechanisms behind the increased sickness absence rates in shared and open-plan offices. However, the literature suggests five main explanations. One explanation could be that increased absence rates in shared and openplan offices are caused by higher exposure to noise in these offices (14). In their review, Passchier-Vermeer \& Passchier (38) found that exposure to noise indoors constitutes a risk in terms of hearing impairment, hypertension, annoyance and sleep disturbance, but there was limited evidence that absence rates were related to noise exposure. Evans (39) found elevated stress hormone in 
subjects exposed to office noise compared to subjects exposed to quiet conditions even when there were no differences in the subjects' perception of stress. Clausen et al (40) found a relation between self-reported noise exposure and long-term sickness absence for men, but not for women. Although the results from other studies are mixed, noise exposure is more prevalent in shared and especially open-plan offices and may be a part of the explanation for the found association.

Another explanation for the association could be that the difference in sickness absence in the various offices is due to differences in the type of ventilation used. Open-plan offices are in general equipped with mechanical ventilation whereas many cellular offices in Denmark have natural ventilation (14). This explanation is supported by other studies $(10,11)$ and the general finding that mechanical ventilation is associated with non-specific symptoms $(12,13)$. However, controlling for type of ventilation in our previous study did not remove the effect of type of office on symptoms (14).

A third explanation for the found association could be that occupants in shared and open-plan offices are more likely to be exposed to viruses than occupants in cellular offices. A recent review showed strong evidence for an association between ventilation, air movements in buildings, and the spread of infectious diseases (41). Even though the number of sources is higher in mechanically ventilated open-plan offices than in naturally ventilated cellular offices, the ventilation rate is in general also higher in open-plan offices, so the resulting exposure for workers in the various types of offices is hard to estimate.

A fourth explanation for the difference in sickness absence between types of offices could be differences in the psychosocial work environment (23). Our previous study neither supported nor contradicted this explanation since we found statistically significant differences in the psychosocial work environment between offices, but the magnitude of the differences was very modest (14). Other studies pointed at lack of privacy as a severe problem in open-plan offices (19).

A final explanation has to do with the presence of other humans when working, and shares similarities with the psychosocial explanation. Working in open-plan or shared offices may reduce employees' autonomy, as the absence of physical boundaries will increase the likelihood that co-workers and leaders will interfere with the employees' discretion and freedom to work (19). Lack of autonomy may be a stressor, as it is related to burnout (42), and therefore can be a contributing factor to sickness absence. Related to this explanation is the evaluation apprehension explanation. Within psychology, studies have shown that working in the presence of others may lead to social facilitation, however if the employees are subject to evaluation apprehension, this may rather lead to inhibition than social facilitation (43). This stressor may therefore also be a contributing factor to sickness absence.

\section{Concluding remarks}

Open-plan offices have become popular because they are designed to facilitate communication and accommodate knowledge sharing. However, our study showed that occupants sharing an office had a significantly higher number of days of sickness absence than those in cellular offices. Consequently, employees, employers, and society in general pay a high price for the benefits of open-plan offices in terms of sickness absence and loss of productivity.

\section{Acknowledgements}

This work was partly supported by the Danish Ministry of Employment as a part of a surveillance programme on occupational health, and partly by the Danish Working Environment Research Fund [Grant no: 20070014615].

\section{References}

1. Whitaker SC. The management of sickness absence. Occup Environ Med. 2001;58:420-4. doi:10.1136/oem.58.6.420.

2. Gimeno D, Benavides FG, Benach J, Amick BC. Distribution of sickness absence in the European Union countries. Occup Environ Med. 2004;61:867-9. doi:10.1136/oem.2003.010074.

3. Henderson M, Glozier N, Holland Elliott K. Long term sickness absence. BMJ. 2005;330:802-3. doi:10.1136/ bmj.330.7495.802.

4. Allebeck P, Mastekaasa A. Chapter 5. Risk factors for sick leave - general studies. Scand J Public Health. 2004;32:49-108. doi:10.1080/14034950410021853.

5. Niemelä R, Seppänen O, Korhonen P, Reijula K. Prevalence of building-related symptoms as an indicator of health and productivity. Am J Ind Med. 2006;49:819-25. doi:10.1002/ ajim. 20370.

6. Danielsson CB, Bodin L. Office type in relation to health, wellbeing, and job satisfaction among employees. Environ Behav. 2008;40:636-68. doi:10.1177/0013916507307459.

7. Jaakkola JJK, Heinonen OP. Shared office space and the risk of the common cold. Eur J Epidemiol. 1995;11:213-6. doi:10.1007/BF01719490.

8. Milton DK, Glencross PM, Walters MD. Risk of Sick Leave Associated with Outdoor Air Supply Rate, Humidification, and Occupant Complaints. Indoor Air. 2000;10:212-21. doi:10.1034/j.1600-0668.2000.010004212.x.

9. Myatt TA, Staudenmayer J, Adams K, Walters M, Rudnick 
SN, Milton DK. A study of indoor carbon dioxide levels and sick leave among office workers. Environ Health. 2002;1:3. doi:10.1186/1476-069X-1-3.

10. Preziosi P, Czernichow S, Gehanno P, Hercberg S. Workplace air-conditioning and health services attendance among French middle-aged women: a prospective cohort study. Int J Epidemiol. 2004;33:1120-3. doi:10.1093/ije/dyh136.

11. Teculescu DB, Sauleau EA, Massin N, Bohadana AB, Buhler O, Benamghar L, Mur JM. Sick-building symptoms in office workers in northeastern France: a pilot study. Int Arch Occup Environ Health. 1998;71:353-6. doi:10.1007/ s004200050292.

12. Mendell MJ. Non-specific symptoms in office workers: A review and summary of the epidemiologic literature. Indoor Air. 1993;3:227-36. doi:10.1111/j.1600-0668.1993.00003.x.

13. Seppänen O, Fisk WJ. Association of ventilation system type with SBS symptoms in office workers. Indoor Air. 2002;12:98112. doi:10.1034/j.1600-0668.2002.01111.x.

14. Pejtersen J, Allermann L, Kristensen TS, Poulsen OM. Indoor climate, psychosocial work environment and symptoms in open-plan offices. Indoor Air. 2006;16:392-401. doi:10.1111/ j.1600-0668.2006.00444.x

15. Fisk WJ, Mendell MJ, Daisey JM, Faulkner D, Hodgson AT, Nematollahi M, Machin D. Phase1 of the California healthy building study: a summary. Indoor Air. 1993;3:246-54. doi:10.1111/j.1600-0668.1993.00005.x.

16. Stenberg B, Mild KH, Sandstrom M, Sundell J, Wall S. A prevalence study of the sick building syndrome (SBS) and facial skin symptoms in office workers. Indoor Air. 1993;3:7181. doi:10.1111/j.1600-0668.1993.t01-2-00002.x.

17. Menzies R, Tamblyn R, Farant JP, Hanley J, Nunes F, Tamblyn R. The effect of varying levels of outdoor-air supply on the symptoms of sick building syndrome. N Engl J Med. 1993;328:821-7. doi:10.1056/NEJM199303253281201.

18. Chao HJ, Schwartz J, Milton DK, Burge HA. The work environment and workers' health in four large office buildings. Environ Health Perspect. 2003;111:1242-8. doi:10.1289/ ehp.5697.

19. De Croon EM, Sluiter JK, Kuijer PPFM, Frings-Dresen MHW. The effect of office concepts on worker health and performance: a systematic review of the literature. Ergonomics. 2005;48:119-34. doi:10.1080/0014013051233 1319409.

20. Banbury SP, Berry DC. Office noise and employee concentration: Identifying causes of disruption and potential improvements. Ergonomics. 2005;48:25-37. doi:10.1080/00 140130412331311390.

21. Brennan A, Chugh JS, Kline T. Traditional versus open office design. A longitudinal field study. Environ Behav. 2002;34:279-99. doi:10.1177/0013916502034003001.

22. Alexanderson K. Sickness absence: a review of performed studies with focused on levels of exposures and theories utilized. Scand J Soc Med. 1998;26:241-9.

23. Duijts SFA, Kant J, Swaen GMH, van den Brandt PA, Zeegers MPA. A meta-analysis of observational studies identifies predictors of sickness absence. J Clin Epidemiol. 2007;60:1105-15. doi:10.1016/j.jclinepi.2007.04.008.

24. North FM, Syme SL, Feeney A, Shipley M, Marmot M. Psychosocial work environment and sickness absence among British civil servants: The Whitehall II Study. Am J Public Health. 1996;86:332-40. doi:10.2105/AJPH.86.3.332.

25. Pejtersen JH, Bjorner JB, Hasle P. Determining minimally important score differences in scales of the Copenhagen Psychosocial Questionnaire. Scand J Public Health. 2010;38:33-41. doi:10.1177/1403494809347024.

26. Feveile H, Olsen O, Burr H, Bach E. Danish work environment cohort study 2005: from idea to sampling design. Statistics in Transition - new series. 2007;8:441-58.

27. Thorsted, BL. Forskerbeskyttelse i CPR. Survey exemption in the Danish Centralized Civil Register. In: Linde, P., editor. Århus University: Statistic Denmark; 2007. p74-84.

28. WHO. Obesity: preventing and managing the global epidemic. Report of a WHO Consultation. Geneva: World Health Organization; 2000. WHO Technical Report Series No. 894.

29. Saltin B, Grimby G. Physiological Analysis of Middle-Aged and Old Former Athletes - Comparison with Still Active Athletes of Same Ages. Circulation. 1968;38:1104-15.

30. Borg V, Kristensen TS, Burr H. Work environment and changes in self-rated health: a five year follow-up study. Stress Med. 2000;16:37-47. doi:10.1002/(SICI)10991700(200001)16:1<37::AID-SMI830>3.0.CO;2-O.

31. Labriola M, Lund T, Burr H. Prospective study of physical and psychosocial risk factors for sickness absence. Occup Med. 2006;56:469-74. doi:10.1093/occmed/kq1058.

32. Christensen KB, Labriola M, Lund T, Kivimäki M. Explaining the social gradient in long-term sickness absence: a prospective study of Danish employees. J Epidemiol Community Health. 2008;62:181-3. doi:10.1136/jech.2006.056135.

33. Podsakoff PM, MacKenzie SB, Lee JY, Podsakoff NP. Common method biases in behavioral research: A critical review of the literature and recommended remedies. J Appl Psychol. 2003;88:879-903. doi:10.1037/0021-9010.88.5.879.

34. Bradburn NM, Rips LJ, Shevell SK. Answering Autobiographical Questions - the Impact of Memory and Inference on Surveys. Science. 1987;236:157-61. doi:10.1126/ science. 3563494 .

35. Camarda CG, Eilers PHC, Gampe J. Modelling general patterns of digit preference. Stat Modelling. 2008;8:385-401. doi:10.1177/1471082X0800800404

36. Ferrie JE, Kivimaki M, Head J, Shipley MJ, Vahtera J, Marmot MG. A comparison of self-reported sickness absence with absences recorded in employers' registers: evidence from the Whitehall II study. Occup Environ Med. 2005;62:74-9. doi:10.1136/oem.2004.013896.

37. Drivsholm T, Eplov LF, Davidsen M, Jorgensen T, Ibsen $\mathrm{H}$, Hollnagel H, Borch-Johnsen K. Representativeness in population-based studies: A detailed description of nonresponse in a Danish cohort study. Scand J Public Health. 2006;34:623-31. doi:10.1080/14034940600607616.

38. Passchier-Vermeer W, Passchier WF. Noise exposure and 
public health. Environ Health Perspect. 2000;108:123-31. doi: $10.2307 / 3454637$.

39. Evans GW, Johnson D. Stress and open-office noise. J Appl Psychol. 2000;85:779-83. doi:10.1037/0021-9010.85.5.779.

40. Clausen T, Christensen KB, Lund T, Kristiansen J. Selfreported noise exposure as a risk factor for long-term sickness absence. Noise Health. 2009;11:93-7. doi:10.4103/14631741.50693.

41. Li Y, Leung GM, Tang JW, Yang X, Chao CYH, Lin JZ, Lu JW, Nielsen PV, Niu J, Qian H, Sleigh AC, Su HJJ, Sundell J, Wong TW, Yuen PL. Role of ventilation in airborne transmission of infectious agents in the built environment - a multidisciplinary systematic review. Indoor Air. 2007;17:2-18. doi:10.1111/ j.1600-0668.2006.00445.x.

42. Lee RT, Ashforth BE. A meta-analytic examination of the correlates of the three dimensions of job burnout. J Appl Psychol. 1996;81:123-33. doi:10.1037/0021-9010.81.2.123.

43. Feinberg JM, Aiello JR. Social facilitation: A test of competing theories. Journal of Applied Social Psychology. 2006;36:1087109. doi:10.1111/j.0021-9029.2006.00032.x.

Received for publication: 23 December 2010 